\title{
ACCIÓN POPULAR DE INCONSTITUCIONALIDAD Y
} DEMOCRACIA ${ }^{1}$

\author{
Paulina González Vergara ${ }^{2}$
}

SUMARIO: I. - Introducción; II. - Acción popular de inconstitucionalidad; A) Legitimación para el ejercicio de la acción de inconstitucionalidad; B) Acción popular de inconstitucionalidad y democracia participativa; III.- A modo de conclusión; IV.- Bibliografía.

RESUMEN: Trata el presente trabajo acerca de la acción de inconstitucionalidad de legitimación amplia o popular, de frente a la de legitimación restringida o institucional, desde la perspectiva de los mecanismos de la democracia semidirecta o participativa. Siguen una serie de reflexiones finales en torno al tema, inspiradas en nuestra realidad nacional.

Palabras clave: Inconstitucionalidad - Legitimación - Democracia Acción Popular - Representatividad.

\section{INTRODUCCIÓN}

Dentro de los distintos aspectos gravitantes para la configuración de la Justicia Constitucional, es fundamental el de la legitimación para dar inicio a los procedimientos de control constitucional, pues de sus características depende en gran medida la eficacia de este control ${ }^{3}$.

A este respecto se han planteado distintas posibilidades, las cuales pueden ser esquematizadas del siguiente modo ${ }^{4}$ :

- Legitimación amplia y obligatoria respecto de todas las autoridades públicas

1 Este trabajo constituye una versión revisada de aquel que sirviera para aprobar el curso de Derecho Constitucional dirigido por el Dr. Raúl Bertelsen Reperto dentro del Programa "Doctorado en Derecho" impartido por la Pontificia Universidad Católica de Chile, durante el primer semestre de 2004.

2 Abogada. Doctorando en Derecho, Pontificia Universidad Católica de Chile. Becaria MECESUP.

3 En este mismo sentido, KelSEN, Hans: La garantía jurisdiccional de la Constitución (La justicia constitucional), trad. por Rolando Tamayo y Salmorán, Instituto de Investigaciones Jurídicas, Serie Ensayos Jurídicos N ${ }^{\circ}$, UNAM, México, 2001, p. 87.

4 Ibíd. p. 87 y ss.; NogueIra ALCALÁ, Humberto: "La justicia constitucional como defensa de la Constitución", en Revista Chilena de Derecho, 1991 Vol, 20 Ns $^{\circ}$ y 3. Tomo I. p 424. 
- Legitimación restringida respecto de determinadas autoridades, órganos públicos o de un cierto número de sus miembros. Como una variante de esta posibilidad, establecimiento de un defensor de la Constitución facultado para iniciar de oficio el procedimiento ante el organismo de control

- Establecimiento de una acción popular

- Establecimiento de la facultad de actuación de oficio del organismo de control constitucional

En el contexto del modelo americano o difuso ${ }^{5}$, la legitimación para el ejercicio del control de constitucionalidad no es un tema problemático, pues este modelo se encuentra asociado al control a posteriori de carácter concreto, de modo que naturalmente, y no podría ser de otra forma, la legitimación corresponde a quien resultaría ser el agraviado, con la aplicación de la norma o acto cuya constitucionalidad se cuestiona.

En el ámbito de los sistemas de control concentrado o europeo ${ }^{6}$ y control mixto de la constitucionalidad ${ }^{7}$, junto al control concreto existe el control abstracto de constitucionalidad, esto es, sin referencia a la aplicación respecto a un caso concreto de la norma o acto cuestionado. El cual se realiza a través de la llamada Acción de Inconstitucionalidad, procedimiento que puede tener el carácter de control previo o a posteriori y puede referirse tanto a normas jurídicas como a actos administrativos.

Este trabajo trata el tema de la acción de inconstitucionalidad de legitimación amplia o popular, de frente a la de legitimación restringida o institucional (II.A); desde la perspectiva de los mecanismos de la democracia semidirecta o participativa (II.B). Siguen una serie de reflexiones finales en torno al tema, inspiradas en nuestra realidad nacional (III).

\section{ACCión POPULAR DE INCONSTITUCIONALIDAD}

\section{A) Legitimación para el ejercicio de la acción de inconstitucionalidad}

La legitimación para el ejercicio de la acción de inconstitucionalidad, en la mayoría de los ordenamientos tiene un carácter institucional y restringido, al establecerse condiciones habilitantes específicas consistentes en el ejercicio de determinadas potestades públicas (ciertas autoridades y órganos del Estado o un cierto número de sus miembros).

Modelo en el cual el control de constitucionalidad es llevado a cabo por el Poder Judicial. Modelo en el cual el control constitucional se encuentra en manos de un órgano especializado. Modelo en el cual se combinan los dos modelos anteriores (por el Poder Judicial y por un órgano especializado), el cual tiene una mayor presencia en el derecho constitucional latinoamericano. 
En el ámbito del derecho europeo ha sido realmente excepcional el establecimiento de una legitimación amplia o popular respecto de la acción de inconstitucionalidad, como fue el caso de la Constitución de Yugoslavia (artículo 387) . $^{8}$

Durante el periodo 1790-1795 se discute en Francia sobre el control de la constitucionalidad?.

En cuanto a la iniciativa de los ciudadanos para que se efectúe dicho control existen dos antecedentes que pueden ser destacados. Uno de ellos, el proyecto montañés presentado por HÊRAULT-SÉCHELLES (1791) establecía en su artículo primero que "Se instituye el gran jurado nacional ${ }^{10}$ para garantizar los derechos frente a la opresión del Cuerpo legislativo y del Consejo". Agregando que "Todo ciudadano oprimido por un acto particular tiene el derecho de recurrir a él"11. Pero este caso no corresponde a una acción popular de inconstitucionalidad, pues no se trata de un control abstracto sino un control concreto a petición del agraviado. Por otra parte, el proyecto relativo al establecimiento de un Tribunal Constitucional presentado por Enmanuel SIEYÈs (1794) al referirse a la cuestión del ámbito de los sujetos facultados para presentar demandas de inconstitucionalidad, es claramente restrictivo en cuanto a la participación de los ciudadanos, pues solo se los facultaba respecto de la protección de sus derechos individuales y ni siquiera se considera la legitimación a los órganos de base popular (asambleas). Restringiendo la legitimación al Consejo de los Ancianos y al de los Quinientos, como también a una minoría de los miembros de tales Consejos ${ }^{12}$.

Sin duda ha sido determinante en la preferencia en el derecho europeo de sistemas de legitimación institucional, la opinión de Hans KeLSEN al respecto, quien al referirse al tema del inicio del procedimiento ante el Tribunal Constitucional señala que "La más fuerte garantía consistiría, ciertamente, en autorizar un actio popularis: así, el tribunal constitucional estaría obligado a proceder al examen de la regularidad de los actos sometidos a su jurisdicción, en especial las leyes y los reglamentos, a solicitud de cualquier particular. Es de esta manera como el interés político que existe en la eliminación de los actos irregulares recibiría, indiscutiblemente la más radical satisfacción. No puede, sin embargo, recomendarse esta solución porque entrañaría un peligro muy grande de acciones temerarias y el riego de insoportable congestionamiento de procesos"13.

Según cita de Nogueira: (n. 4), p. 424.

Blanco Valdés, Roberto L.: El valor de la Constitución. Alianza Editorial, Madtid, 1994, pp. 181 y ss.

10 El cual se encontraría compuesto por los ciudadanos elegidos por las Asambleas primarias de los discintos departamentos. Ibíd. P. 281.

Ibíd.

Ibíd., p. 299.

Kelsen, Hans: (n. 3), pp. 87-88. 
En el ámbito del derecho constitucional latinoamericano la situación es diferente, pues existen varios ordenamientos que contemplan la legitimación popular ${ }^{14}$.

La Constitución salvadoreña $(1983)^{15}$, la nicaragüense (1987), la venezolana $(1999)^{16}$ y la colombiana $(1991)^{17}$ establecen que se podrá declarar la inconstitucionalidad a petición de cualquier ciudadano.

La Constitución peruana $(1993)^{18}$ dispone entre quienes se encuentran facultados para ejercer la acción de inconstitucionalidad a cinco mil ciudadanos, y a los colegios profesionales, en materias de su especialidad.

14 BREWER-CARIAS, Allan R.: "La jurisdicción constitucional en América Latina", en La Jurisdicción Constitucional en Iberoamérica. Dykinson, S.A., Madrid, 1997, p 117; Eguiguren Prael.t, Francisco: Los Tribunales Constitucionales en Latinoamérica: una visión comparativa. CIEDLA, Buenos Aires, 2000. LOSING, Norbert: La jurisdiccionalidad constitucional en Latinamérica. Dykinson, S.L. Madrid, 2002. Base de Datos contenida en http://www.georgetown.edu/pdba/Constitutions/constudies.html

15 "Art. 183.- La Corte Suprema de Justicia por medio de la Sala de lo Constitucional será el único tribunal competente para declarar la inconstitucionalidad de las leyes, decretos y reglamentos, en su forma y contenido, de un modo general y obligatorio, y podrá hacerlo a petición de cualquier ciudadano".

16 "Artículo 333. Esta Constitución no perderá su vigencia si dejare de observarse por acto de fuerza o porque fuere derogada por cualquier otro medio distinto al previsto en ella. En tal eventualidad, todo ciudadano investido o ciudadana investida o no de autoridad, rendrá el deber de colaborar en el restablecimiento de su efectiva vigencia".

"Artículo 241. A la Corte Constitucional se le confía la guarda de la integridad y supremacía de la Constitución, en los estrictos y precisos términos de este artículo. Con tal fin, cumplirá las siguientes funciones: 1 . Decidir sobre las demandas de inconstitucionalidad que promuevan los ciudadanos contra los actos reformatorios de la Constitución, cualquiera que sea su origen solo por vicios de procedimiento en su formación. 4.- Decidir sobre las demandas de inconstitucionalidad que presenten los ciudadanos contra las leyes, tanto por su contenido material como por vicios de procedimiento en su formación. 5.Decidir sobre las demandas de inconstitucionalidad que presenten los ciudadanos contra los decretos con fuerza de ley dictados por el Gobierno con fundamento en los artículos 150 numeral 10 y 341 de la Constitución, por su contenido material o por vicios de procedimiento en su formación. 10. Decidir definitivamente sobre la exigibilidad de los tratados internacionales y de las leyes que los aprueben. Con tal fin, el Gobierno los remitirá a la Corte, dentro de los seis días siguientes a la sanción de la ley. Cualquier ciudadano podrá intervenir para defender o impugnar su constitucionalidad. Si la Corte los declara constitucionales, el Gobierno podrá efectuar el canje de notas; en caso contrario no serán ratificados. Cuando una o varias normas de un tratado multilateral sean declaradas inexequibles por la Corte Constitucional, el Presidente de la República solo podrá manifestar el consentimiento formulando la correspondiente reserva.

"Artículo 242 1. Cualquier ciudadano podrá ejercer las acciones públicas previstas en el artículo precedente, e intervenir como impugnador o defensor de las normas sometidas a control en los procesos promovidos por otros, así como en aquellos para los cuales no existe acción pública".

18 "Artículo 203. Están facultados para interponer acción de inconsticucionalidad: 5. Cinco mil ciudadanos con firmas comprobadas por el Jurado Nacional de Elecciones. Si la norma es una ordenanza municipal, está facultado para impugnarla el uno por ciento de los ciudadanos del respectivo ámbito territorial, siempre que este porcentaje no exceda del número de firmas anteriormente señalado; 7. Los colegios profesionales, en materias de su especialidad". 
En la Constitución panameña $(1994)^{19}$ se contiene la norma más amplia en la materia, al establecer que se encuentra legitimada cualquier persona.

La Constitución ecuatoriana $(1998)^{20}$ faculta para demandar de inconstitucionalidad a mil ciudadanos, o a cualquier persona que cuente con el respaldo del Defensor del Pueblo.

La Constitución guatemalteca $(1999)^{21}$, por su parte, establece entre quienes se encuentran legitimados activamente para plantear la inconstitucionalidad a la junta Directiva del Colegio de Abogados, y a cualquier persona respaldada por tres abogados.

La acción popular de inconstitucionalidad presenta en los distintos ordenamientos que la consagran las siguientes características comunes:

a) Acción popular-no necesariamente acción pública: La acción popular de inconstitucionalidad excepcionalmente tiene el carácter de una acción pública, en el sentido de que pueda ser ejercida por cualquier persona, sino más bien se establecen algunas restricciones legitimando a los ciudadanos (individualmente o se requiere la concurrencia de un determinado número) o a ciertos organismos gremiales. En cuanto al requisito de la ciudadanía, la legitimación para el ejercicio de esta acción es entendida como un derecho-deber de carácter político. En algunas constituciones debe ser entendida en el contexto de los deberes políticos, en el sentido de deber de cumplir y velar por el cumplimiento de la Constitución, como es el caso de El Salvador (artículo $73 \mathrm{n}^{\circ} 2$ ) y de deber de colaborar por el restablecimiento de su vigencia efectiva, como es el caso de Venezuela (artículo 333). En otras constituciones, debe ser entendida en el contexto de los derechos políticos, en tanto modo de hacer efectivo el derecho de los ciudadanos de fiscalizar los actos públicos, como es

19 "Artículo 203.- La Corte Suprema de Justicia tendrá, entre sus atribuciones constitucionales y legales, las siguientes: 1. La guarda de la integridad de la Constitución para la cual la Corte en pleno conocerá y decidirá, con audiencia del Procurador Géneral de la Nación o del Procurador de la Administración, sobre la inconstitucionalidad de la Leyes, decretos, acuerdos, resoluciones y demás actos que por razones de fondo o de forma impugne ante ella cualquier persona...".

20 "Artículo 277.- Las demandas de inconstitucionalidad podrán ser presentadas por: 5. Mil ciudadanos en goce de derechos políticos, o cualquier persona previo informe favorable del Defensor del Pueblo sobre su procedencia, en caso de las demandas de inconstitucionalidad, de fondo o de forma, relativas a leyes orgánicas y ordinarias, decretos-leyes, decretos, ordenanzas; estaturos, reglamentos y resoluciones, emitidos por órganos de las instituciones del Estado y en caso de las demandas de inconstitucionalidad de los actos administrativos emitidos por las autoridades públicas (artículo 276 números 1 y 2)".

21 "Artículo 134. Legitimación activa. Tiene legitimación para plantear la inconstitucionalidad de leyes, reglamentos o disposiciones de carácter general: a) La junta Directiva del Colegio de Abogados, actuando a través de su Presidente; d) Cualquier persona con el auxilio de tres abogados colegiados activos". 
el caso de Venezuela (artículo 333); o en términos más amplios, en tanto modo de hacer efectivo el derecho de participación en la conformación, ejercicio y control del poder político, como es el caso de Colombia (artículo 42).

De lo anterior, resulta que el carácter popular de esta acción no implica necesariamente su carácter de acción pública, como podría pensarse en un primer momento, sino que se relaciona con el hecho de que su ejercicio no se encuentra limitado a determinados funcionarios u órganos del Estado.

b) Mecanismo de control abstracto de constitucionalidad: La acción popular de inconstitucionalidad es siempre un mecanismo de control abstracto de constitucionalidad, esto es, sin referencia a la aplicación respecto a un caso concreto de la norma cuestionada de modo que quien la ejerce no necesita acreditar un interés específico.

c) Efectos erga omnes: En tanto mecanismo de control abstracto de constitucionalidad, la acción popular de inconstitucionalidad que resulta ser acogida tiene siempre efectos generales, en cuanto conlleva la anulación de la norma cuestionada.

d) Mecanismo de control de constitucionalidad a posteriori: Todas las constituciones que establecen acciones populares de inconstitucionalidad la regulan como un mecanismo de control de constitucionalidad a posteriori, esto es, respecto de normas vigentes o actos dictados y no respecto de proyectos normativos.

En algunos ordenamientos, junto a la acción popular de inconstitucionalidad se establece además el derecho de los ciudadanos de intervenir en las acciones de inconstitucionalidad interpuestas por otras personas (ciudadanos o legitimación específica) ${ }^{22}$ y en este último caso, este derecho de intervención podría ejercerse respecto de un proceso de control previo de constitucionalidad.

Las anteriores son las características comunes que presenta en los distintos ordenamientos que contemplan la acción popular de inconstitucionalidad. Sin embargo, existen algunas diferencias principalmente respecto a su campo de aplicación y al momento en que puede ser ejercida.

En cuanto a su campo de aplicación, en la mayoría de los casos se la establece respecto de las distintas clases de leyes en sentido estricto y de las normas de carácter general dictadas por el Poder Ejecutivo. Excepcionalmente se la contempla respecto de otra clase de normas, como es el caso de la Constitución colombiana (1991) que establece una acción popular de inconstitucionalidad respecto de reformas constitucionales en que se ha incurrido en vicios de forma (artículo $241 \mathrm{n}^{\circ} 1$ ); y respecto de

22 Como el caso de la Constitución colombiana (artículo 241.1), ver nota 8. 
actos administrativos, como es el caso de Panamá (1994) 23 $^{23}$ de Ecuador $(1998)^{24}$.

En cuanto al momento en que puede ser ejercida, algunos ordenamientos establecen la existencia de un plazo de prescripción para su interposición. Tal es el caso de la Constitución peruana (1993) la que señala que la acción de inconstitucionalidad de una norma debe interponerse dentro del plazo de seis meses contado desde su publicación (artículo 26), plazo que en todo caso se refiere a toda acción de inconstitucionalidad y no solo a las de carácter popular.

En Chile, desde el establecimiento del Tribunal Constitucional el control abstracto de la constitucionalidad de las leyes y decretos ha sido concebido como un mecanismo de defensa institucional de la Constitución, pues se ha reservado el ejercicio de la acción de inconstitucionalidad al Presidente de la República, a las Cámaras del Congreso o a un cierto porcentaje de sus miembros.

Los temas que se han discutido dentro de los distintos aspectos referentes a la configuración de la Justicia Constitucional en nuestro país, a nivel de la doctrina como en el ámbito de la tramitación de proyectos de reforma constitucional, han sido principalmente los relativos a la integración, generación y responsabilidad de los miembros del Tribunal Constitucional, su competencia y el efecto de sus resoluciones ${ }^{25}$.

La legitimación para el ejercicio de la acción de inconstitucionalidad no ha sido un tema que se haya encontrado mayormente en debate. Sin embargo, aunque aislados han existido algunos antecedentes relativos a concepciones que conciben la acción de inconstitucionalidad también como un mecanismo de defensa popular y no solo institucional de la supremacía constitucional.

La segunda reforma contenida en el Proyecto Alessandri-Ortúzar de 1964 respecto al control de la constitucionalidad, proponía el establecimiento de una acción popular de inconstitucionalidad de conocimiento de la Corte Suprema ${ }^{26}$.

"La Corte Suprema a petición de cualquier ciudadano deberá declara inconstitucional cualquier precepto legal contrario a la Constitución

23 Artículo $203 \mathrm{n}^{\circ} 1$ de la Constitución Política. Ver nota 10.

24 Artículo $277 \mathrm{n}^{\circ} 5$ de la Constitución Política. Ver nota 11.

25 A modo ilustrativo, Andrade Geywitz, Carlos: "Proposiciones del grupo de estudios constitucionales sobre el Tribunal Constitucional" y ATrIA LEMAITRE, Fernando: "El Tribunal Constitucional y la objeción democrática"; ambos artículos en Revista Chilena de Derecho, 1991 Vol. $20 \mathrm{~N}^{\circ}$ s 2 y 3. Tomo I. pp. 361 y 367 respectivamente; ZúÑIGA Urbina, Francisco. "Jurisdicción Constitucional en Chile. Balance Crítico", en Tribunales y Justicia Constitucional, Memoria del VII Congreso Iberoamericano de Derecho Constitucional, Instituto de Investigaciones Jurídicas, Serie Documentos Jurídicos $n^{n}$ 105. UNAM. México 2002, pp. 441 y ss.

26 BERTELSEN REPETTO, Raúl: Sistemas de control de constitucionalidad entre 1960 y 1989 , Pp. 195 y ss. 
Política del Estado, sea en la forma de su generación o en su contenido de fondo.

Esta petición deberá fallarse dentro de 30 días hábiles de interpuesta.

Acogido el recurso de inconstitucionalidad, la Corte Suprema ordenará publicar de inmediato el fallo respectivo en el "Diario Oficial" y, a partir de la fecha de esta publicación, el precepto inconstitucional dejará de producir efectos sin que esta declaración pueda afectar las sentencias ejecutoriadas dictadas con anterioridad a dicha publicación" 27.

En el contexto de la aprobación de la Constitución Política de 1980, no se plantea la posibilidad del establecimiento de una acción popular de inconstitucionalidad. De la ausencia de debate a este respecto, parece quedar de manifiesto que para nuestros constituyentes la única posibilidad en la materia es la del establecimiento de una legitimación de carácter institucional y restringida ${ }^{28}$.

A nivel de la doctrina, dentro de un conjunto de reformas necesarias para la plena vigencia del Estado Constitucional de Derecho en nuestro país, se ha propuesto por una parte, el establecimiento de una acción popular de inconstitucionalidad ante el Tribunal Constitucional respecto de los decretos con fuerza de ley, los reglamentos y otros decretos; y por otra, el establecimiento del derecho de intervención de "cualquier persona del pueblo" en los procesos de control preventivo de la constitucionalidad ${ }^{29}$.

A nivel de proyectos de reforma constitucional, durante la vigencia de la actual Constitución Política no se ha propuesto derechamente el establecimiento de una acción popular de inconstitucionalidad, sin embargo, existió una propuesta que consideraba ampliar la legitimación institucional en el sentido de la concurrencia de un cierto porcentaje de ciudadanos ${ }^{30}$.

El proyecto planteaba la incorporación de un $\mathrm{n}^{\circ} 13$ al artículo 82 de la Constitución Política con el fin de incorporar entre las atribuciones del Tribunal Constitucional la de "resolver sobre la inconstitucionalidad de preceptos legales que se presente ya sea por un senador o por dos diputados, acompañados de las firmas de al menos un $0,5 \%$ de los electores inscritos en la región o distrito respectivo", añadiendo que "en caso de tratarse de diputados de diferentes distritos, deberá reunirse un número

Ibíd., p. 201.

En general existe consenso en torno a la regulación relativa al Tribunal Constitucional, los temas que suscitan mayor controversia son los referidos a la posible acusación política de los miembros del tribunal (Ses. 365". 3/5/78. Vol. 10 pp. 2460 a 2462) y en cuanto a su competencia, el planteamiento de la inconstitucionalidad de decretos y reglamentos (Ses. 359 26/4/78. Vol. 10 pp. 2357 a 2364).

REYES RIVEROS, Jorge: "Supremacía constitucional y sistema nacional de control", en Revista Chilena de Derecho, 1991 Vol. $20 \mathrm{~N}^{\circ}$ s 2 y 3. Tomo I. p. 452

Moción ingresada al senado con fecha 6 de diciembre de 1994, la cual fue rechazada en el primer trámite constitucional con fecha 14 de noviembre de 1995 . 
de firmas igual al del $0,5 \%$ de los electores del distrito que tenga un mayor número de inscritos en sus registros electorales".

Además, se proponía la incorporación al mismo artículo de un inciso final, en el cual se establecía que "en el caso del número 13, el Tribunal, si considera que el precepto es inconstitucional, lo declarará derogado para todos los efectos, derogación que regirá desde la fecha en que se publique extracto de la sentencia en el "Diario Oficial" y que, además, deberá ser comunicada a los Presidentes de cada Cámara del Congreso Nacional".

Finalmente, respecto del conjunto de reformas constitucionales actualmente en tramitación, se ha señalado que se trataría de una reforma incompleta no solo porque no se extiende el control de constitucionalidad sobre determinadas normas y actos que deberían ser revisables, sino también porque "no consagra una acción o recurso de constitucionalidad directa y de carácter abstracto con sentencia de efecto personal erga omnes sino una anacrónica inaplicabilidad, probadamente insatisfactoria en más de medio siglo de jurisprudencia, en la que además de exige tres fallos uniformes y unánimes para que opere el efecto personal general"31

\section{B) Democracia y acción popular de inconstitucionalidad}

Pensar la democracia en el sentido de participación directa de los ciudadanos en el ejercicio del poder, al estilo del modelo griego durante la Antigüedad o de algunos cantones suizos hasta nuestros días, solo es posible respecto de Estados pequeños. Pues una efectiva participación de todos o la gran mayoría de los ciudadanos implica un número reducido de los mismos y un territorio de no gran extensión; por otra parte, la dirección exitosa de sociedades más complejas conlleva la necesidad de que las decisiones sean tomadas por quienes cuenten con ciertos conocimientos y habilidades determinadas ${ }^{32}$.

\section{Zúñiga: (n, 25), p. 533.}

Junto a tales argumentos, se ha criticado la democracia directa señalando que en general quienes toman las decisiones son grupos oligárquicos; que se diluye la responsabilidad de los líderes, los que siempre existen, al aparecer que el pueblo es el que gobierna; que favorece la influencia en la toma de decisiones de oradores hábiles y no necesariamente defensores de los intereses generales; que por su propia naturaleza no permite la toma de decisiones serias y reposadas respecto de los asuntos de gobierno, lo que puede favorecer graves desórdenes; y que no es factible respecto de sociedades no uniformes en que existen una pluralidad de intereses. En este sentido, EsCOBAR FOrNOS, Iván: "El sistema representativo y la democracia semidirecta", en Sistema representativo y democracia semidirecta, Memoria del VII Congreso Iberoamericano de Derecho Constitucional, Instituto de Investigaciones Jurídicas, Serie Doctrina Jurídica $\mathrm{n}^{\circ}$ 100. UNAM, México, 2002, pp. 138-139. Nuestra opinión al respecto es que tales peligros pueden también afectar, y así ha quedado demostrado, a las democracias representativas; de modo que, creemos que la impracticabilidad de la democracia directa estriba fundamentalmente en las razones apuntadas en el texto principal. 
Por lo anterior es que desde los inicios de la modernidad la democracia se consolida en tanto democracia representativa ${ }^{33}$, en la cual la participación de los ciudadanos se centra principalmente en la configuración del poder a través del mecanismo de las votaciones populares, de forma que las autoridades se encuentran legitimadas democráticamente en cuanto a su origen, de un modo directo, aquellas que son elegidas por los ciudadanos, e indirectamente, aquellas que son nombradas por tales autoridades. Sistema en que los partidos políticos juegan un importante papel en la articulación y mediación entre los distintos grupos de intereses coexistentes en la sociedad y en la generación de los representantes.

Pero más allá de esta legitimidad de origen y en cuanto tal de naturaleza formal, la legitimidad de fondo de este sistema de gobierno tiene su fundamento en la efectiva adecuación en el ejercicio del poder por parte de las autoridades, con los intereses generales y las exigencias del bien común.

En el contexto de las sociedades contemporáneas la crisis de la democracia representativa se produce precisamente con la pérdida de tal legitimidad de fondo, crisis cuyo advenimiento se explica a partir de las siguientes razones: i) la falta de vigencia efectiva de los derechos y libertades proclamadas formalmente; ii) el desprestigio de la clase política y de los partidos políticos, en tanto instituciones oligárquicas que restringen la participación a determinados segmentos sociales y por ende, carentes de la representatividad que debe caracterizarlos por responder a intereses personales o de grupos económicos o de poder; y iii) la falta de preparación de las autoridades que les permitan la toma oportuna y eficaz de medidas necesarias para solucionar los problemas sociales con miras a la consecución del bien común ${ }^{34}$.

La respuesta a esta crisis de la representatividad presenta dos vertientes: aquella que propone la instauración de formas de gobierno totalitarias y por ende, en frontal oposición con los valores verdaderamente democráticos y aquellas que desde la democracia proponen en el marco de la democracia representativa la introducción de mecanismos de democracia directa, conformándose la llamada democracia semidirecta o partici-

\footnotetext{
33 La cual se encuentra asentada sobre la base de los siguientes elementos o condiciones: i) el principio de la soberanía popular; ii) el principio de la representación popular; iii) el principio de la consagración y protección de los derechos y deberes en la Constitución Política; iv) el principio de la separación de poderes; v) el principio del pluralismo político, que se manifiesta en el rechazo al partido político único y en la igualdad de oportunidades de los distintos partidos políticos para acceder al poder. Ibib., p. 135. miento de los Partidos políticos. Documentos UAPROL/BCN/ año IV $\mathrm{n}^{\circ} 047$. Es ilustrativo considerar que se ha señalado que el porcentaje de quienes opinan que es posible la democracia sin Parlamento ha bajado de un 63\% a un 52\% entre los años 1997 a 2002; y en igual período, ha bajado de un $62 \%$ a un $52 \%$ respecto de quienes opinan que es posible la democracia sin partidos políticos, p. 4. (http://www.latinobarometro.org).
} 
pativa $^{35}$. La cual supone un concepto amplio de participación, en cuanto mayor injerencia de la ciudadanía, no solo en la configuración del poder político mediante votaciones populares destinadas a la generación de las autoridades políticas, sino también en su ejercicio y control.

En este contexto la participación en los asuntos públicos se constituye como un derecho de los ciudadanos, cuyo reconocimiento es indispensable para la consecución del bien común ${ }^{36}$.

Tradicionalmente la doctrina ha señalado como los principales mecanismos propios de la democracia semidirecta o participativa a los siguientes ${ }^{37}:$ i) el referéndum: consulta en que la ciudadanía se manifiesta sobre proyectos constitucionales o legales (consultivo) o sobre la aprobación o anulación de normas constitucionales, legales o de actos administrativos (ratificatorio); mecanismo que puede tener el carácter de facultativo u obligatorio; ii) el plebiscito; consulta a la ciudadanía relativa a materias territoriales o políticas; iii) la iniciativa popular: facultad de los ciudadanos de presentar peticiones relativas a la dictación de las leyes o de presentar proyectos de ley; iv) la revocación del mandato: la facultad de los ciudadanos de provocar el retiro de determinadas autoridades antes del vencimiento del plazo de su mandato; v) el veto popular: revocación por parte de la ciudadanía de leyes vigentes a iniciativa de un cierto número de ciudadanos; vi) la apelación de sentencia: sometimiento al voto popular de las leyes declaradas inconstitucionales por el órgano de control constitucional.

Entre tales mecanismos, los que han tenido una mayor aceptación a nivel mundial son el referéndum y el plebiscito, respecto del resto, se encuentran consagrados principalmente en el ámbito del derecho constitucional latinoamericano.

Si bien se han señalado varias ventajas respecto de los mecanismos de participación directa, tales como, que contribuyen a acentuar el control y la responsabilidad de las autoridades y su cercanía con los problemas e intereses de la ciudadanía, ayudan a la disminución de la apatía

35 Un completo estudio sobre la teoría e instituciones de la democracia participativa en SiLva JimÉnez, Ana María: La Democracia Semidirecta, en el campo de la teoría, de las instituciones y su marco jurídico en nuestro país. Tesis. Pontificia Universidad Católica de Chile, Santiago, 1995.

36 En este sentido, la Constitución venezolana establece "Arcículo 62. Todos los ciudadanos y ciudadanas tienen el derecho de participar libremente en los asuntos públicos, directamente o por medio de sus representantes elegidos o elegidas. La participación del pueblo en la formación, ejecución y control de la gestión pública es el medio necesario para lograr el protagonismo que garantice su completo desartollo, tanto individual como colectivo. Es obligación del Estado y deber de la sociedad facilitar la generación de las condiciones más favorables para su práctica".

37 DE LA MADRID, Miguel: "Las formas de la democracia directa", en Sistema representativo y democracia semidirecta, Memoria del VII Congreso Iberoamericano de Derecho Constitucional, Instituto de Investigaciones Jurídicas, Serie Doctrina Jurídica $\mathrm{n}^{\circ} 100$, UNAM, México, 2002, pp. 431 y ss. Escobar, F.: (32), pp. 141 y ss. Silva, J.: (35), pp. 145 y ss. 
política, mantienen un grado más razonable de confrontación y conflicto en la consecución del poder político entre los distintos grupos de intereses y favorecen la negociación y cooperación, porque quienes resulten derrotados no quedan totalmente marginados al contar con cauces formales de participación ${ }^{38}$; también se han dejado de manifiesto sus inconvenientes, críticas que apuntan principalmente a la falta de preparación de los ciudadanos, al peligro de su utilización por gobiernos totalitarios y populistas, su alto costo de implementación y la posible opresión de las minorías ${ }^{39}$. Por otra parte, desde el punto de vista práctico se ha criticado que en aquellos países en que se han introducido estos mecanismos, su uso ha sido más bien moderado sin importar un aumento significativo en la participación de los ciudadanos ni tampoco se ha podido comprobar un efecto positivo respecto de su representatividad en relación a las autoridades y los partidos políticos ${ }^{40}$.

Aun cuando la acción popular de inconstitucionalidad no ha sido incluida por los autores entre los mecanismos propios de la democracia participativa, no cabe duda que tiene su misma naturaleza al posibilitar la participación directa de los ciudadanos en el control de constitucionalidad. Si bien en un principio podría pensarse que se trataría de una especie de veto popular, en un sentido más amplio, pues puede referirse no solo a leyes sino también a otras normas jurídicas (decretos, reglamentos y resoluciones) y a actos administrativos, y en otro sentido más restringido, pues si bien los ciudadanos mantienen la facultad de iniciativa propia del veto, la anulación no se decide por votación popular, es esta última característica la que le otorga autonomía.

El que la decisión sobre la anulación de la norma o acto impugnado no sea tomada por votación popular, sino por un órgano especializado apunta a la naturaleza del control, en el primer caso se trata de un control político, el que puede o no involucrar un examen de constitucionalidad

Escobar, F.: (n. 32), pp. 147-148. RoDrIK, Dani: "¿Por qué hay tanta inseguridad económica en América Latina?", en Revista de la CEPAL, $\mathrm{n}^{\circ}$ 71, abril 2001, pp. 28-29. Son interesantes las ideas de este autor, respecto a la correlación existente entre participación y seguridad económica, el cual no es un análisis que se hace muy comúnmente al tratar esta materia y que debiera tener mayor atención debido a su importancia. Al respecto ha señalado que "Los datos de los diversos países sugieren que sociedadaes con mayor apertura y participación política se ajustan mejor a las perturbaciones externas, experimentan menor volatilidad económica y generan menor inflación. Por ende, la institucionalización de la democracia debería producir en definitiva resultados económicos más estables y aliviar la inseguridad económica", p. 28.

39 Ibíd, p, 147.

40 Un completo estudio sobre la práctica de estos mecanismos en nuestro continente, Zovatto G., Daniel: "La Práctica General de las instituciones de la democracia directa en América Latina. Un balance comparado: 1978-2000", en Sistema representativo y democracia semidirecta, Memoria del VII Congreso Iberoamericano de Derecho Constitucional, Instituto de Investigaciones Jurídicas, Serie Doctrina Jurídica n 100 , UNAM, México, 2002, pp. 891 y ss. 
ya que nada impide que resulte la anulación de leyes conformes a la Constitución Política por razones de oportunidad o de conveniencia de su dictación; y en el segundo caso, se trata de un control jurídico pues lo revisado es la conformidad de la norma o acto impugnado respecto de la norma fundamental. Es también esta característica la que convierte a este mecanismo en uno más seguro respecto de los peligros anteriormente señalados. Seguridad que es aún mayor respecto de acciones populares de inconstitucionalidad condicionadas (legitimación de cierto número de ciudadanos o determinados grupos de la sociedad civil, exclusión de determinados tipos de leyes o actos y existencia de un plazo de prescripción).

\section{A MODO DE CONCLUSIÓN}

Chile no se ha mantenido al margen del fenómeno global de crisis de representatividad que ha afectado a las democracias contemporáneas ${ }^{41}$, la que en nuestro país desembocó, con las consecuencias que todos conocemos en cuanto a violaciones de derechos humanos, en un gobierno totalitario al que luego siguió uno autoritario. Ambos con un importante apoyo popular.

A más de una década de vuelta a un gobierno democtático, la legitimidad de nuestro sistema es cuestionada constantemente ${ }^{42}$, de modo que no podríamos decir que hemos avanzado en cuanto a la superación de la crisis de representatividad que lo viene afectando desde hace ya mucho tiempo. Es urgente abordar eficazmente esta situación para que esta vez la respuesta frente a la crisis sea "más democracia" y no su negación como lo fue en el pasado.

Por eso es que consideramos que en el Chile de hoy, se precisa reflexionar junto con el fortalecimiento de la democracia representativa y sus instituciones, también sobre los mecanismos de participación de la ciudadanía como medios de hacer que nuestra democracia sea realmente representativa de los intereses generales y eficiente en la consecución del bien común. Reconocemos los peligros que pueden conllevar tales mecanismos de participación en la forma en que han sido concebidos, pero convencidos de su necesidad y beneficio creemos que es posible su

4t Fenómeno que se manifiesta en lo que se ha denominado "desafección política", siendo una de sus principales consecuencias la falta de participación en los procesos de votación popular. Sobre este tema en relación a nuestro país, CALLIS R., Axel. Legitimidad democrática y padrón electoral, en: http://www.eclac.cl/publicaciones/SecretariaEjecutiva/0/ LCG2130/lcg2130e_1.pdf.

42 En este sentido CAZOR ALISTE, Kamel: "Algunas reflexiones en torno al actual desarrollo democrático de la sociedad chilena, a la luz de la articulación entre democracia política y democracia constitucional", en Estudios Constitucionales, Universidad de Talca, 2003, p. 17. 
reformulación en términos más seguros y útiles o que debe buscarse la creación de otros mecanismos de participación que presenten tales características. $Y$ en este ámbito, tiene sentido analizar en nuestro medio mecanismos como la acción popular de inconstitucionalidad, que como señalamos es un instrumento de participación que conlleva los beneficios de la misma sin acarrear los peligros que pudieran entrañar los restantes mecanismos de participación o lo hace en mucho menor medida.

\section{BiBLIOGRAFÍA}

- Andrade Geywitz, Carlos: "Proposiciones del grupo de estudios constitucionales sobre el Tribunal Constitucional", en Revista Chilena de Derecho, 1991 Vol. $20 \mathrm{~N}^{\circ}$ s 2 y 3. Tomo I.

- Atria Lemaitre, Fernando: "El Tribunal Constitucional y la objeción democrática", en Revista Chilena de Derecho, 1991 Vol. 20 Nos 2 y 3. Tomo I,

- BeRTELSEN REPETTO, Raúl: Sistemas de control de constitucionalidad entre 1960 y 1989.

- Blanco Valdés, Roberto L.: El valor de la Constitución. Alianza Editorial, Madrid, 1994.

- Brewer-CARíAs, Allan R.: "La jurisdicción constitucional en América Latina", en La Jurisdicción Constitucional en Iberoamérica, Dykinson, S.A., Madrid, 1997.

- Callis R., Axel: Legitimidad democrática y padrón electoral, en http:// www.eclac.cl/publicaciones/SecretariaEjecutiva/0/LCG2130/ Icg2130e_1.pdf

- De la MADRID, Miguel: "Las formas de la democracia directa", en Sistema representativo y democracia semidirecta, Memoria del VII Congreso Iberoamericano de Derecho Constitucional, Instituto de Investigaciones Jurídicas, Serie Doctrina Jurídica n 100, UNAM, México, 2002.

- Eguiguren Praeli, Francisco: Los Tribunales Constitucionales en Latinoamérica: una visión comparativa. CIEDLA, Buenos Aires, 2000.

- ESCOBAR FORNOS, Iván: "El sistema representativo y la democracia semidirecta", en Sistema representativo y democracia semidirecta, Memoria del VII Congreso Iberoamericano de Derecho Constitucional, Instituto de Investigaciones Jurídicas, Serie Doctrina Jurídica $\mathrm{n}^{\circ} 100$, UNAM, México, 2002.

- Kelsen, Hans: La garantía jurisdiccional de la Constitución (La justicia constitucional), trad. por Rolando Tamayo y Salmorán, Instituto de Investigaciones Jurídicas, Serie Ensayos Jurídicos, $\mathrm{N}^{\circ}$, UNAM, México, 2001.

- Losing, Norbert: La jurisdiccionalidad constitucional en Latinoamérica. Dykinson, S.L. Madrid, 2002. 
- Nogueira Alcalá, Humberto: "La justicia constitucional como defensa de la Constitución", en Revista Chilena de Derecho, 1991 Vol. 20 Nos 2 y 3. Tomo I.

- Reyes RIVERos, Jorge: "Supremacía constitucional y sistema nacional de control", en Revista Chilena de Derecho, 1991 Vol. $20 \mathrm{~N}^{\circ}$ s 2 y 3. Tomo I.

- Rodrik, Dani: “¿Por qué hay tanta inseguridad económica en América Latina?", en Revista de la CEPAL, $\mathrm{n}^{\circ}$ 71, abril 2001.

- Silva Jiménez, Ana María: La Democracia Semidirecta, en el campo de la teoría, de las instituciones y su marco jurídico en nuestro país, Tesis, Pontificia Universidad Católica de Chile, Santiago, 1995.

- Turiz Lazcano, Alejandro: Fortalecimiento de los Partidos políticos. Documentos UAPROL/BCN/ año IV n ${ }^{\circ} 047$.

- Zovatto G., Daniel: "La Práctica General de las instituciones de la democracia directa en América Latina. Un balance comparado: 1978-2000", en Sistema representativo y democracia semidirecta, Memoria del VII Congreso Iberoamericano de Derecho Constitucional, Instituto de Investigaciones Jurídicas, Serie Doctrina Jurídica $\mathrm{n}^{\circ}$ 100. UNAM, México, 2002.

- Zuñiga Urbina, Francisco: "Jurisdicción Constitucional en Chile. Balance Crítico", en Tribunales y Justicia Constitucional, Memoria del VII Congreso Iberoamericano de Derecho Constitucional, Instituto de Investigaciones Jurídicas, Serie Documentos Jurídicos $\mathrm{n}^{\circ} 105$, UNAM, México 2002. 